\title{
OS LIMITES DE RESPONSABILIZAÇÃO DO GESTOR PÚBLICO NAS CONTRATAÇÕES EM VIRTUDE DA PANDEMIA DE CORONAVÍRUS
}

\section{THE LIMITS OF RESPONSIBILITY OF THE PUBLIC MANAGER IN HIRING DUE TO THE CORONAVIRUS PANDEMIC}

\author{
Guilherme Firmo da Silveira Alves*
}

\begin{abstract}
RESUMO
O Estado possui muitas funções para oferecer o bem-estar da sociedade e tais funções são feitas por meio de seus agentes públicos que atuarão com eficiência, moralidade e sempre visando o melhor interesse público. Com a pandemia do Coronavírus, a Administração Pública necessitou tomar decisões mais céleres com o objetivo de salvar vidas e diminuir a propagação do vírus. Logo, durante o processo de tomada de decisões, é possível que o agente público cometa erros por causa da falta de diligências e pela falta de segurança jurídica. Decerto, o gestor público só será responsabilizado em razão de culpa grave ou gravíssima. As decisões da administração pública são acompanhadas pelos órgãos de controle, com o objetivo de assegurar o interesse público. Assim, devido ao controle das decisões administrativas, o Direito Brasileiro determina um espaço para a responsabilidade do gestor público em virtude de suas decisões; a existência de espaço de tolerância do erro é necessária para que se preserve a eficiência e economicidade das atividades públicas. Em cenários de incerteza e urgência como vivido atualmente, a tolerância ao erro deverá ser flexibilizada e analisada de caso a caso e não de forma geral e genérica. Ademais, em caso de possível responsabilização deverá ser verificado de forma minuciosa, garantido o contraditório, ampla defesa do agente público.
\end{abstract}

Palavras-chave: Erro do agente público. Direito Administrativo. COVID-19.

\begin{abstract}
The State has many functions to provide the welfare of society and such functions are performed through its public agents who will act with efficiency, morality and always aiming at the best public interest. With the Coronavirus pandemic, the Public Administration needed to take faster decisions in order to save lives and reduce the spread of the virus. Therefore, during the decision-making process, it is possible for the public agent to make mistakes due to lack of diligence and lack of legal certainty. Of course, the public manager will only be held responsible for serious or very serious fault. The decisions of the public administration are monitored through the control bodies, with the objective of assuring the public interest. Thus, due to the control of administrative decisions, Brazilian Law determines a space for the responsibility of the public manager by virtue of his decisions, the existence of a space for error tolerance is necessary to preserve the efficiency and economy of public activities. In scenarios of uncertainty and urgency as currently experienced, error tolerance should be relaxed and analyzed on a case-by-case basis and not in a general and generic way. In addition, in case of
\end{abstract}

\footnotetext{
Artigo submetido em 20 de dezembro de 2021 e aprovado em 14 de fevereiro de 2022.

* Graduado em Direito pela Faculdade Mineira de Direito da Pontifícia Universidade Católica de Minas Gerais (FMD. PUC Minas).

Pós Graduando em Direito Civil e Processual Civil - Lato Sensu pelo Gran Cursos Online. E-mail: firmo.guilherme@yahoo.com.
} 
Artigo: Os Limites de Responsabilização do Gestor Público nas Contratações em Virtude da Pandemia de Coronavírus

possible liability, it must be verified in detail, guaranteeing the contradictory, broad defense of the public agent.

Keywords: Public agent error. Administrative Law. COVID-19.

\section{INTRODUÇÃO}

Em 2020 o mundo foi surpreendido pela pandemia de Coronavírus (COVID19); uma doença com grau de mortalidade significativa vem assolando a humanidade em diversos fatores, e os governantes tentam contê-la.

No que tange ao combate a doenças altamente contagiosas, a Administração Pública necessita de uma célere tomada de decisões para evitar a disseminação do vírus, com isso surge a necessidade de aquisição de materiais e serviços diversos. Logo, inúmeros processos de compras foram inaugurados em todas as esferas da federação, visando adquirir os bens necessários para o combate à pandemia. Com o surgimento de novas legislações, decretos e resoluções que visam a celeridade do procedimento de aquisição de bens e serviços para o enfrentamento da enfermidade, agora, o trâmite de compras torna-se mais fácil e menos burocrático, em comparação ao rito comum em que o administrador público está acostumado.

Entretanto, em decorrência da necessária celeridade do processo de aquisição desses bens ou serviços surgiu uma insegurança jurídica em decorrência de que as novas normas não foram objetos de interpretações consolidadas por falta de tempo, ocasionando decisões menos diligentes e refletivas.

Como é sabido, o princípio da segurança jurídica é um mandamento basilar no Estado Democrático de Direito, ele se atrela à atividade humana, na confiabilidade, certeza de direito, previsibilidade, calculabilidade e estabilidade às relações jurídicas em decorrência da interpretação da norma. Tal princípio visa a proteção do gestor público ao valer-se de precedentes da administração pública, devendo tomar a decisão que achar o melhor para o interesse público. Contudo, o erro é inerente ao ser humano. Logo, caberá a Administração Pública buscar parâmetros de tolerância ao erro cometido por um de seus representantes.

A problemática deste artigo diz respeito à aplicação da tolerância ao erro e o grau de culpa exigido do administrador público para que este seja responsabilizado em virtude de suas decisões. O ponto de partida vem da falta de interpretação de uma nova lei por parte dos órgãos de controle que deveria garantir a segurança e confiança em sua tomada de decisão do administrador. Esta lei poderá acarretar em decisões que de início poderão ser as mais sensatas para o interesse público, mas que poderão gerar inúmeros danos tanto ao erário quanto à população em geral.

Logo, se existe um espaço de tolerância ao erro diante da tomada de decisões do gestor público, como isto será aplicado no caso concreto? A resposta para esse problema perpassa a compreensão do princípio da segurança jurídica e pela caracterização do dolo e do erro grosseiro.

O marco teórico está relacionado à realização da segurança jurídica como princípio que norteia todo o Direito brasileiro tomado na perspectiva de Humberto Ávila e Paulo de Barros Carvalho e sua importância na aplicabilidade do Direito Administrativo nas decisões públicas.

A hipótese está relacionada à garantia da segurança jurídica como princípio basilar acompanhados dos princípios da eficiência e moralidade que deverão ser observados pelo agente público no processo de tomada de decisões seja em caso de normalidade ou em casos de grande complexibilidade. Além, há de se considerar o princípio da segurança jurídica como preceito de um Estado Democrático de Direito que deverá ser respeitado já que a noção de segurança lhe é ínsita. 


\section{A PANDEMIA DO CORONAVÍRUS E A GESTÃo PÚBLICA BRASILEIRA}

No final do ano de 2019, na cidade chinesa de Wuhan, surgiram casos de pneumonia de origem desconhecida; logo, de maneira acelerada o vírus tomou conta da cidade chinesa, tendo sido necessária a adoção de medidas restritivas para conter a sua disseminação.

Ao se alastrar de maneira descontrolada, em 11 de março de 2020, o diretor geral da OMS, Tedros Adhanom, elevou o grau da contaminação à situação de pandemia devido a rapidez da infeção de pessoas.

No Brasil, o primeiro caso foi notificado em 26 de fevereiro de 2020 e hoje, em 2022 soma o total de mais de 20 milhões de pessoas que foram infectadas pela enfermidade. A pandemia acarretou crise no sistema de saúde brasileiro, seja ele público ou privado. A falta de medicamentos para a utilização nas UTI, mais conhecidos como kit intubação, o aumento do desemprego, da situação de vulnerabilidade social e a falta de insumos para o combate da doença são dados de uma triste realidade na vida dos brasileiros. Em situações de anormalidade como vivida atualmente, o ordenamento jurídico reconhece e autoriza medidas atípicas para atender o interesse público.

Assim foi publicado o Decreto Legislativo $\mathrm{n}^{\circ}$ 6/2020 que reconheceu o estado de calamidade pública e em seguida foi publicada a Lei $\mathrm{n}^{\circ}$ 13.979/2020 que dispõe sobre as medidas que a Administração Pública deverá tomar em face da crise sanitária. Há inovações trazidas pela Lei $\mathrm{n}^{\circ}$ 13.979/2020, como a adoção de isolamento, quarentena, entre outras medidas de proteção.

No que tange a contratação, o art. $4^{\circ}$ da Lei no $13.979 / 2020$, dispensa-se a licitação para a aquisição de bens ou serviços, inclusive de engenharia ou compra de insumos e até mesmo com empresa impedida de contratar com o poder público, tudo com o objetivo do enfrentamento da situação de saúde emergencial.

Relevante ressaltar a importante decisão do Supremo Tribunal Federal por meio da Medida Cautelar na Ação Direta de Inconstitucionalidade (ADI) nº 6341: não se afasta a competência dos Estados, Municípios e Distrito Federal a tomarem decisões que acharem necessárias para combater o novo coronavírus.

Neste momento vivido pela sociedade brasileira, a Administração Pública tem como dever resguardar o direito à saúde de toda população. Neste sentido, Gilmar Mendes (2018) define o direto de defesa e proteção à saúde como:

O direito à vida apresenta evidente cunho de direito de defesa, a impedir que os poderes públicos pratiquem atos que atentem contra a existência de qualquer ser humano. Impõe-se também a outros indivíduos, que se submetem ao dever de não agredir esse bem elementar (MENDES, 2018, p. 265).

A Lei $n^{\circ} 13.979 / 2020$ veio com o objetivo de trazer segurança jurídica aos gestores em sua tomada de decisões, na mesma linha, observa-se que em decorrer do cenário de emergência, a segurança jurídica se encontra em risco em decorrência da necessidade de que a tomada de decisão deverá ser célere, muitas vezes, dependendo da situação do caso concreto, o agente público não conseguirá realizar todas as diligências necessárias para a ação ao enfrentamento, o que poderá causar o erro nas decisões do agente público.

A segurança jurídica é de fato um diferencial ao ordenamento jurídico, o agente público sempre deverá basear suas ações de forma harmônica com este princípio. Vislumbrando as linhas de Humberto Ávila (2004):

O princípio da segurança jurídica é construído de duas formas. Em primeiro lugar, pela interpretação dedutiva do princípio maio do Estado de Direito (art. $1^{\circ}$ ). Em segundo lugar, pela interpretação indutiva de outras regras constitucionais, 
Artigo: Os Limites de Responsabilização do Gestor Público nas Contratações em Virtude da Pandemia de Coronavírus

nomeadamente as de proteção do direito adquirido, do ato jurídico perfeito e da coisa julgada (art. $5^{\circ}$, XXXVI) e da anterioridade (art. 150, III, “b”). Em todas essas normas, a Constituição Federal dá uma nota de previsibilidade e de proteção de expectativa legitimamente constituída e que, por isso mesmo, não podem ser frustradas pelo exercício da atividade estatal. (ÁVILA, 2004, p. 295).

Torna-se relevante averiguar se o erro cometido devido ao cenário de incerteza na tomada de decisões feita pelo agente público será cabível de responsabilização por este, e, se caso confirmado, qual será os limites desta responsabilização.

\section{A DECISÃO DO GESTOR PÚBLICO NO ÂMBITO DO PROCESSO DE COMPRAS EM CARÁTER DE EXCEPCIONALIDADE}

Em condições normais, o administrador público demoraria certo tempo para que se realize pesquisa sobre certo bem, preço ou serviço e seria realizado estudo técnico e jurídico a respeito da matéria, no entanto, em se tratando de emergência na saúde pública, muitas vezes essas ações tornam-se impossíveis de serem realizadas.

Dispõe o art. 37, inciso XXI da CF/88 sobre a obrigatoriedade da Administração Pública de licitar quando tem por objetivo adquirir bens ou serviços e ressalva "os casos especificados na legislação".

Em casos de normalidade, a Lei $n^{\circ}$ 8.666/93 exige a licitação para obras, serviços, compras, alienações, concessões e permissões que observará o documento convocatório por meio de edital ou de carta convite, a habilitação que observará os requisitos mínios aos participantes se adequarem as exigências da capacitação e idoneidade para celebrar contrato com administração pública.

As empresas enfrentam um processo bastante burocrático e desgastante na apresentação dos documentos para a formalização do feito. O Ministro Adylson Motta, do Tribunal de Contas da União posicionou-se a respeito da formalidade excessiva da administração pública ao tratar da formalização da licitação.

O apego a formalismos exagerados e injustificados é uma manifestação perniciosa da burocracia que, além de não resolver apropriadamente problemas cotidianos, ainda causa dano ao Erário, sob o manto da legalidade estrita. Esquece o interesse público e passa a conferir os pontos e vírgulas como se isso fosse o mais importante a fazer. Os princípios da proporcionalidade e razoabilidade acarretam a impossibilidade de impor consequências de severidade incompatível com a irrelevância de defeitos. Sob esse ângulo, as exigências da Lei ou do edital devem ser interpretadas como instrumentais. (TC 004809/1999-8, Decisão 695-99, DOU 8/11/99, p.50, e BLC n. 4, 2000, p. 203).

A Lei de Licitações trouxe especificadamente no art. 24, IV a dispensa da licitação nos casos de emergência ou calamidade pública, com o prazo para conclusão de 180 (cento e oitenta) dias e é necessário a urgência no atendimento e a possibilidade de prejuízo ou comprometer a segurança da população, de serviços ou bens públicos ou particulares.

Di Pietro (2014) entende que a dispensa de licitação, referente ao art. 24, IV da Lei no 8666/1993, deverá observar o princípio da razoabilidade através da relação entre os meios e os fins. Di Pietro entende que estado de calamidade pública e situação de emergência como:

O estado de calamidade pública está definido pelo Decreto ${ }^{\circ} 7.257$, de 4-8-10, que regulamenta a Medida Provisória n ${ }^{\circ} 494$ de 2-7-2010 (convertida na Lei nº 12.340, de $1^{\circ}$-12-10), para dispor sobre o Sistema Nacional de Defesa Civil - SINDEC. O artigo $2^{\circ}$ define a situação de emergência como "situação anormal, provocada por desastres, causando danos e prejuízos que impliquem o comprometimento parcial da capacidade 
de resposta do poder público do ente atingido" (inciso III); e estado de calamidade pública "situação anormal, provocada por desastres, causando danos e prejuízos que impliquem o comprometimento substancial da capacidade de resposta do poder público do ente atingido (inciso IV). (DI PEITRO, 2014, p. 399).

A princípio, com a leitura do art. 24, IV da Lei $n^{\circ} 8.666 / 1993$, nota-se que ele se encaixa perfeitamente na situação em que o Brasil se encontra em decorrência da pandemia do Coronavírus (COVID-19); o que, em um primeiro momento, faz surgir a possibilidade de aplicação do dispositivo supracitado.

A lei $n^{\circ}$ 13.979/2020 acrescida com as alterações da Medida Provisória $n^{\circ}$ 926/2020 (convertida na Lei ${ }^{\circ}$ 14.035/2020), autoriza a dispensa temporária da realização de licitação para a aquisição de bens, serviços e insumos, contratação direta desde que seja com o objetivo de combate ao coronavírus.

Em geral, a contratação necessita de um planejamento, que se adeque aos meios necessários e regras impostas sobre suas condições: declarar o objeto, identificar a real necessidade, elaborar uma solução, critérios de medição e pagamento, adequação orçamentária, pesquisa de preço e manifestação da autoridade competente, e que, nesses casos, poderá ter seus procedimentos dispensados.

A mudança de regra do regime de aquisição em situação considerada normal com a que vivenciamos hoje, traz um enorme significado. O principal motivo, que é indiscutível para a desburocratização das contratações ou compra de insumos vem com a extrema urgência em que o Estado se encontra; com o reconhecimento de calamidade pública, as coisas mudam, agora a Administração pública precisa agir de maneira célere. O tempo será considerado um luxo ao administrador público em tempos de pandemia.

O objetivo das mudanças nas contratações é o de trazer a eficiência e celeridade no processo de compras públicas em decorrência da grave situação que o mundo se encontra. $\mathrm{O}$ gestor público espera que seja empregada a boa-fé e honestidade, uma vez que a quebra de burocracias tem como o principal objetivo salvar vidas.

\section{DOS ÓRGÃOS DE CONTROLE NO ÂMBITO ADMINISTRATIVO}

Em suas funções, a Administração Pública fica sujeita ao controle do Poder Legislativo e Judiciário e, por ela mesma em seus próprios atos.

O controle tem como objetivo assegurar que a Administração atue em consonância com a legalidade, moralidade, finalidade pública e entre outros princípios que regem a Administração Pública. Um princípio de grande relevância é o da legalidade, sendo um dos pilares para os atos da função administrativa, pois parte da pressuposição que o ente público exerce suas ações em observância à lei.

Pietro (2020):

A fiscalização e revisão são funções essenciais dos órgãos de controle. Preceitua Di

Com base nesses elementos, pode-se definir o controle da Administração Pública como o poder de fiscalização e correção que sobre ela exercem os órgãos dos Poderes Judiciário, Legislativo e Executivo, com o objetivo de garantir a conformidade de sua atuação com os princípios que lhe são impostos pelo ordenamento jurídico. (DI PIETRO, 2020, p. 931).

A existência dos órgãos de controle é essencial para limitar a Administração Pública no poder de decidir, coibindo as instituições públicas de desvios de verbas públicas ou até mesmo de decisões ilegais. O controle sobre a Administração Público é um exercício da democracia em busca da efetividade, legalidade, moralidade e eficiência do ente público. 
Artigo: Os Limites de Responsabilização do Gestor Público nas Contratações em Virtude da Pandemia de Coronavírus

\title{
4.1 O controle público e o princípio da eficiência
}

As atividades oriundas da Administração Pública deverão basear-se no princípio da legalidade, moralidade, impessoalidade, publicidade e eficiência, sendo submetida ao controle seja do Executivo, legislativo ou até mesmo do Judiciário.

O controle sobre os órgãos da Administração Pública advém da própria Administração Pública com o intuito de rever seus atos ilegais ou inconvenientes exercendo o poder de autotutela.

O princípio da eficiência veio com a EC n 19/1998, acrescentando ao caput do art. 37 a eficiência como sendo a qualidade do serviço prestado pelo ente público.

Conforme Almeida (2020):

Essa eficiência deverá atingir não só os agentes públicos como também apropria Administração. Os agentes públicos deverão atuar, da melhor forma pos- sível, na busca dos melhores resultados. Já a Administração deverá estruturar de forma racional sua organização, de modo a atingir os melhores resultados a um menor custo possível. (ALMEIDA, 2020, p. 50).

O objetivo desse princípio é a busca pela economia do dinheiro público e a busca de efetiva produtividade da administração pública, com isso, surge o controle como um poder de verificação em face dos órgãos e agentes administrativos para buscar se realmente os atos administrativos estão atendendo de fato o interesse público.

No que tange ao controle na esfera do Poder Legislativo, cujos membros são representantes do povo deve analisar as condutas administrativas como um todo atuando diretamente ou com auxílio de Controladoria ou Tribunal de Contas respectivo. O Legislativo deve analisar os critérios financeiros e políticos em face das tomadas de decisão do Administrativo, uma vez que o poder regido pelo executivo será o de executor de direitos em prol da sociedade.

Já no âmbito judicial o controle é sobre a legalidade de determinado ato da administração e por fim, pela própria administração pública, por meio do controle interno podese fiscalizar e analisar os seus próprios atos.

O Judiciário busca a harmonização entre os atos praticados pela Administração Pública e as leis.

Salienta Carvalho Filho (2020):

\begin{abstract}
A importância do controle judicial, convém que se diga, é mais destacada se levarmos em conta os direitos e garantias fundamentais, estatuídos na Constituição. O Judiciário, por ser um Poder equidistante do interesse das pessoas públicas e privadas, assegura sempre um julgamento em que o único fator de motivação é a lei ou a Constituição. Assim, quando o Legislativo e o Executivo se desprendem de seus parâmetros e ofendem tais direitos do indivíduo ou da coletividade, é o controle judicial que vai restaurar a situação de legitimidade, sem que o mais humilde indivíduo se veja prejudicado pelo todo-poderoso Estado. (CARVALHO FILHO, 2020, p. 1092).
\end{abstract}

O controle judicial exercerá sobre a legalidade dos atos, sendo assim, caso determinado ato administrativo confronte a Constituição ou lei, caberá ao poder judiciário impedir que tais atos produzam efeitos no mundo real.

Note-se então, a relevante importância do controle público exercido sobre a Administração Pública para verificar se as políticas públicas estão sendo aplicadas de modo a trazer benefícios à sociedade, com transparência, eficiência e publicidade submetidos a primazia da legalidade. 


\subsection{A autonomia dos órgãos de controle e sua importância para a Administração Pública}

Para um efetivo exercício da fiscalização sobre os atos administrativo é necessário que órgãos de controle possuam plena autonomia para exercer livremente suas atribuições, nas funções de apuração de irregularidades e de orientar os gestores para adotarem a melhor prática de gestão.

A Lei $n^{\circ} 4.320 / 1964$, a Lei de Responsabilidade Fiscal e a CR/88 exigem a adoção de controle interno na Administração Pública. Com o Estado Democrático de Direito demonstra-se a verdadeira importância do controle e a garantia da aplicação dos princípios fundamentais do ordenamento jurídico brasileiro, trazendo consigo segurança jurídica, tanto ao Estado, quanto aos seus servidores, para que decisões possam ser tomadas com fulcro no respaldo legal e para a publicidade e efetividade da ordem social.

\subsection{A tratativa conferida pelos órgãos de controle ao erro do gestor e a cultura da punição alçada a salvaguarda do interesse público}

É necessário a existência de um controle externo para fiscalizar as decisões tomadas pela Administração Pública, uma vez que seu objetivo tem como a repressão da improbidade e da corrupção, algo bem comum no Brasil.

Note-se que o avanço do controle externo da Administração Pública decorre da CR/88 que veio com o objetivo de físcalização, em decorrência de um histórico em que o gestor público seria aquela pessoa de má-fé. Portanto, é inegável que sob a égide do texto constitucional renovou-se a Administração Pública fazendo-a adotar a eficiência, a democracia e o principal, tomar suas medidas baseadas no interesse público.

Logo, surge a cultura pelo excesso de controle sob o administrador público, que se resume em: quanto mais controle, melhor seria o serviço prestado pela Administração Pública.

O exercício do controle externo da Administração Pública no Brasil tem gerado graves disfuncionalidades no modo exercício da função pública, com sérias consequências para gestão eficiente de recursos públicos e no modo de tomada de decisão. (SANTOS, 2021, p. 121).

A fama de que o órgão público é um lugar em que há falta de ética ainda é um pensamento bem comum perante a sociedade civil, e acaba tornando os agentes públicos reféns do controle dos órgãos de controle; além da pressão desses órgãos, cujo objetivo é fiscalizar suas ações, percebe-se que a pressão da sociedade civil também sustenta essa reputação.

Os órgãos de controle possuem grande intolerância aos erros cometidos pelos agentes públicos, observe-se, portanto, que parte dos órgãos de controle não realiza busca minuciosa se de fato tal erro é injustificável ou não conforme o art. 22, caput e $\$ 1^{\circ}$ da Lei de Introdução às Normas do Direito Brasileiro (LINDB).

Como diz Dionísio (2020):

A intolerância ao cometimento de equívocos decisórios por administradores públicos parece encontrar fundamento teórico em uma concepção tradicional do princípio da legalidade administrativa, bem como na suposta superioridade dos interesses representados pelo Estado, crença que foi incorporada pelo Direito Administrativo brasileiro por meio dos princípios da supremacia e da indisponibilidade do interesse público. (DIONÍSIO, 2020, p. 35).

Conclui-se que as causas e efeitos do controle externo acabam criando uma cultura do medo sobre os gestores públicos. Ao falar em cultura do medo significa que o agente público terá medo de ser responsabilidade sobre sua tomada de decisões logo, se priorizando por motivos de autoproteção ocasionando prejuízo do interesse público. 
Artigo: Os Limites de Responsabilização do Gestor Público nas Contratações em Virtude da Pandemia de Coronavírus

\section{A TEORIA DO ERRO AO DIREITO ADMINISTRATIVO BRASILEIRO}

O ser humano é passível de cometer erros, e isso cabe ao agente público, muitas vezes, por falta de tempo, recursos, inúmeras informações que são ignoradas e incapaz de processar de forma perfeita.

O erro no Direito Administrativo é pouco estudado, diferentemente do que se observa no âmbito do Direito Civil e Direito Penal. A necessidade de um espaço da tomada de decisão e da responsabilização em virtude do erro, dá segurança ao gestor público para que ele possa saber os critérios para decidir suas decisões e como será realizado a fiscalização pelos órgãos de controle em face de suas decisões.

Além da inovação do art. 28 da LINDB, que trouxe um espaço jurídico entre a responsabilização do erro cometido pelo agente público, a Constituição Federal já preceituava o espaço de tolerância ao erro do gestor.

$\mathrm{O}$ art. 28 da LINDB trouxe um espaço de tolerância do agente público em virtude do seu erro, seja ele por dolo ou erro grosseiro que acarretará tanto em responsabilidade civil ou administrativa, seja por improbidade administrativa, danos ao erário ou ao que for mais compatível conforme o caso concreto.

"Art. 28. O agente público responderá pessoalmente por suas decisões ou opiniões técnicas em caso de dolo ou erro grosseiro." (BRASIL, 2018).

Para Santos (2020), o Direito Administrativo busca delimitar o espaço de faculdade do administrador público aplicando meios para que os órgãos de controle possam verificar e consequentemente aplicar as penalidades praticadas em decorrência de seu erro.

Logo, nota-se que para o agente público de fato seja responsabilizado, será necessária uma ação grave e de bastante relevância para a Administração Pública.

\section{A RESPONSABILIDADE DO ADMINISTRADOR PÚBLICO EM RAZÃO DE SEU ERRO, SOB A LUZ DO DIREITO AO ERRO. O ADMINISTRADOR PÚBLICO PODE ERRAR?}

Os atos praticados pelo agente público transparecem a vontade do Estado garantindo coletivos que sobressaem aos individuais, tudo em prol do interesse público e resguardando direitos e garantias fundamentais.

É importante salientar a responsabilidade do Estado em face de seus atos praticados por meio da Teoria do Risco Administrativo em que o ente estatal deverá responder pelos riscos praticados (CARVALHO FILHO, 2020). O Estado sempre será responsabilizado quando praticar ato ilícito que fere os princípios de um Estado Democrático de Direito, este, de modo estrito deverá sempre obedecer ao princípio da legalidade.

Mas ora, o como dito, os atos do ente público são editados por seus agentes públicos dotados de competência, que deverão obedecer a limitação para sua responsabilidade e de espaço para sua tolerância, mas em determinados casos, o agente poderá ser responsabilizado por seus atos em virtude do art. 28 da LINDB.

O Direito brasileiro concede ao administrador público tolerância ao cometimento de erros conforme explicado no tópico anterior. Logo, é notório que o princípio da eficiência e segurança jurídica é de grande importância para a decisão do gestor público.

Todavia, ocorre que em cenários atípicos como pandemia, por exemplo, o administrador público terá posicionamento totalmente diferente daquelas que ele enfrenta em tempos de "normalidade". Em situação de calamidade pública, o tempo é curto, a demanda de compras de equipamentos ou contratação de serviços aumenta e o gestor precisa concluir em menor tempo e com mais agilidade pois se trata de vidas em jogo. 
Em tempos de normalidade, o gestor possui um tempo maior para pesquisar o que será mais eficiente para o interesse público, com isso, ele realizará diligências até chegar em sua decisão final. Todavia, por se tratar de pandemia não significa que o administrador público será isento de todos erros que ele pratica, sempre será necessária a análise do caso concreto.

O art. 28 da LINDB, determina de forma clara, o espaço de tolerância ao erro advindo do gestor público, apenas erros grosseiros deverão ser penalizados em virtude de dano ao erário. Importante observar o cenário em que se encontra o mundo e que poderá acarretar em uma tomada de decisão contendo vícios, em virtude do menor tempo de realizar diligências necessárias para tomar uma decisão segura.

Porém, existem decisões tomadas em tempos de pandemia que não possui nenhum cunho de rapidez e emergência, é necessário ver se a decisão tomada pelo agente é de fato de extrema urgência, como por exemplo a compra de respiradores pulmonares, insumos para o procedimento da intubação de pacientes no CTI, compra de oxigênio que demonstra uma urgência.

\subsection{Limites à responsabilização do gestor público em decorrência de sua tomada de decisão errada, em contexto de pandemia}

Mesmo com a Lei $\mathrm{n}^{\circ} 13.555 / 2018$ que estabeleceu os limites de responsabilização do gestor público em sua tomada de decisões e o Decreto $n^{\circ}$ 9.830/2019 é nítido que em momentos de calamidade pública, como este vivido agora em decorrência da pandemia do novo coronavírus, o administrador público possua mais medo em tomar decisões.

Assim foi editada a MP n ${ }^{\circ}$ 966/2020 que trata da responsabilidade do agente público em relação as tomadas de decisão em caráter emergencial. A MP já determina que a responsabilidade do gestor público não será derivada de culpa simples e sim a responsabilização civil e administrativa pautada no erro grosseiro ou no dolo.

A MP alcança os atos administrativos praticados durante a pandemia e que tenham o objetivo de diminuir os riscos da crise sanitária, porém, o mesmo dispositivo legal foi alvo de discussões na comunidade jurídica sobre os aspectos constitucionais do texto, com isso, o STF por meio das ADIs 6421, 6422, 6424, 6425, 6427, 6428 e 6431 MC fixou o entendimento será erro grosseiro o ato praticado pelo que violar o direito à vida, à saúde ou ao meio ambiente em virtude da inobservância de critérios científicos e técnicos.

O agente competente deverá realizar diligências para tomar sua decisão que deverá sempre buscar as técnicas recomendadas por organismos ou entidades reconhecidas e que sua decisão seja fundamentada na preservação do direito à vida, direito protegido por força constitucional.

\subsection{Processo Administrativo Disciplinar: Importância da ampla defesa e contraditório}

Para apurar os atos ilícitos cometidos pelos agentes públicos é necessário instauração de Processo Administrativo Disciplinar (PAD) e o uso da sindicância em busca da verdade. A Administração Pública poderá punir seus servidores pelas infrações funcionais cometidas por eles.

O PAD, portanto, é uma investigação interna no qual o órgão, autarquia, fundações ou outros entes vinculados a Administração Pública para apurar possíveis infrações cometidas por seus servidores.

É importante saber que todo PAD é fruto de uma denúncia de infração, (nem sempre, a Administração pode agir de ofício) em que essa denúncia poderá levar à abertura de uma sindicância (que não faz parte do PAD), a sindicância é apenas uma apuração para verificar se de fato houve a pratica um ato ilícito e a autoria. 
Artigo: Os Limites de Responsabilização do Gestor Público nas Contratações em Virtude da Pandemia de Coronavírus

A instrução do PAD sempre deverá garantir ao acusado o direito de ampla defesa, pelos meios e recursos elencados no art. 143 da Lei n $^{\circ}$ 8.112/1990.

Para que seja dado o efetivo direito de o indiciado exercer seu direito de ampla defesa e contraditória, Di Pietro (2020) salienta a importância da devida citação do acusado antes de iniciada a instrução para que ele possa elaborar sua tese de defesa, elencar testemunhas e apresentar todos os meios legais que comprovarão sua inocência.

A importância do contraditório e ampla defesa é fundamental em um Estado Democrático de Direito, uma vez que ninguém poderá ser processado sem ter a ciência de que é parte ré de um processo e muito menos que haja limite em apresentar a sua defesa. O processo, seja ele judicial, administrativo ou o PAD como tratado neste capítulo, sempre irá buscar a verdade processual, com isso, é importante a participação tanto daquele que acusa o agente público de cometimento de determinado ato passível de instauração do PAD e ao administrador público que se torna ré em um PAD demonstrar todas as razoes de fato e de direito que é inocente, logo, exercendo sua ampla defesa e contraditório, princípios que são constitucionalmente protegidos.

\subsection{A exigência do erro grosseiro para a responsabilização}

A Lei $\mathrm{n}^{\circ}$ 13.655/2018 incluiu o art. 28 na LINDB, com o objetivo de garantir a eficiência nas funções administrativas.

Conforme o texto do dispositivo legal:

"Art. 28. O agente público responderá pessoalmente por suas decisões ou opiniões técnicas em caso de dolo ou erro grosseiro." (Incluído pela Lei no 13.655 , de 2018).

Note-se que o agente público se refere ao servidor público estatutário, aos empregados públicos regidos pelo sistema celetista, agentes políticos e comissionados, logo, agente público será toda a pessoa que exerça determinada função pública e até mesmo aquele que gerencia recursos públicos. Com isso, agente público será o mesmo taxado na Lei de Improbidade Administrativa. (BINENBOJM e CYRINO, 2018).

O enunciado $\mathrm{n}^{\circ} 18$ emitido pelo Instituto Brasileiro de Direito Administrativo (IBDA), em 14 de junho de 2019 dispõe o seguinte "A LINDB é norma jurídica que impacta todas as regras de direito público, especialmente aquelas que tratam da responsabilização dos agentes públicos que decidem ou emitem opiniões técnicas".

Assim, ocorrerá dolo quando o agente realizar determinado ato que seja contrário aos princípios da Administração Pública. O problema de demonstrar o dolo é pois uma ação de caráter subjetivo do ser humano, o que dificulta a prova. Já o erro grosseiro poderia ser um elemento mais fácil de ser comprovado, pois se dá a noção de erro como algo decidido pelo agente que tenha uma falsa percepção da realidade.

Mas o que se pergunta é, o que seria erro grosseiro? Logo, foi publicado o Decreto $\mathrm{n}^{\mathrm{o}}$ 9.830/2019, complementando a segurança jurídica no que deu o significado de erro grosseiro, sendo este:

\footnotetext{
Art. 12. O agente público somente poderá ser responsabilizado por suas decisões ou opiniões técnicas se agir ou se omitir com dolo, direto ou eventual, ou cometer erro grosseiro, no desempenho de suas funções.

$\S 1^{\circ}$ Considera-se erro grosseiro aquele manifesto, evidente e inescusável praticado com culpa grave, caracterizado por ação ou omissão com elevado grau de negligência, imprudência ou imperícia.
}

Note-se que o art. 12 do Decreto ${ }^{\circ} 9.830 / 2019$ foi bem mais preciso do que o art. 28 da LINDB ao definir o que seria erro grosseiro, mostrando que tal erro não seria qualquer ato 
provocado pelo agente público que causaria em sua responsabilidade; sendo praticado apenas por meio de culpa grave que inclui situações de grave negligência, imprudência ou imperícia.

A Administração exige que não pode haver falhas e nem equívocos. Sendo estes destacados pelos órgãos de controle, serão aplicáveis as devidas sanções e, uma vez admitidas nos moldes do art. 28 da LINDB, é possível associar o erro grosseiro à culpa grave pois ambos afetarão o direito ou um bem jurídico tutelado e tal ação configurada como erro grosseiro terá um grau de culpa de natureza grave ou gravíssima sendo impossível justificar o afastamento da responsabilidade do agente público.

O Acordão $\mathrm{n}^{\circ}$ 2.391/2018 emitido pelo TCU teve como objetivo identificar como ocorrerá o erro grosseiro para a aplicabilidade do art. 28 da LINDB sendo:

83. Tomando como base esse parâmetro, o erro leve é o que somente seria percebido e, portanto, evitado por pessoa de diligência extraordinária, isto é, com grau de atenção acima do normal, consideradas as circunstâncias do negócio. O erro grosseiro, por sua vez, é o que poderia ser percebido por pessoa com diligência abaixo do normal, ou seja, que seria evitado por pessoa com nível de atenção aquém do ordinário, consideradas as circunstâncias do negócio. Dito de outra forma, o erro grosseiro é o que decorreu de uma grave inobservância de um dever de cuidado, isto é, que foi praticado com culpa grave.

Entende-se então que o erro grosseiro seria uma culpa qualificada, grave. O dispositivo supracitado deu uma segurança jurídica maior ao gestor público em sua tomada de decisões, diferentemente do que preceitua o art. $37, \S 6^{\circ}$ da Constituição da República, no qual este seria responsável em casos de culpa ou dolo.

Por se tratar de um conceito novo no ordenamento jurídico, a caracterização do erro grosseiro perante o caso concreto é que o art. 28 da LINDB é recente, necessitando de uma jurisprudência e doutrina pacífica. Outro ponto é analisar a conduta do agente, o dolo não é tão difícil para demonstrar, porém, a culpa grave, que é assemelhado ao erro grosseiro é de caráter subjetivo, sendo difícil de ser analisado e comprovado, tendo que averiguar a real situação que o agente público se encontrava, as diligencias que lhe foram tomadas, o cargo em que ele se encontra poderá ser um fator determinante para a comprovação do erro.

\section{CONSIDERAÇÕES FINAIS}

Após explorar a problemática deste trabalho em torno dos princípios da segurança jurídica e eficiência e como estes influenciam no Direito Administrativo, verifica-se que os órgãos de controle possuem extrema importância na transparência e efetividade nas funções administrativas, sendo através deles corrigidos os erros cometidos pelos agentes públicos e são estes os principais a coibirem o desvio de verbas públicas promovendo a democracia brasileira.

É nítido que o controle da atividade administrativa é algo extremamente necessário no combate a conduta arbitrárias, ímprobas e ilegais com o objetivo de resguardar o interesse público. Por um outro lado, este mesmo controle possui características de ineficiência em decorrência do excesso de burocracia no processo de fiscalização da atividade administrativa acarretando na cultura pelo excesso do controle e do medo na Administração Pública.

A limitação da responsabilidade e o direito ao erro do gestor público tem como marco a redação da LINDB, que limita a responsabilização do agente público em caso de erro grosseiro ou dolo que acarreta uma segurança ao agente público em seu processo de tomada de decisão.

A Administração Pública exerce atividade delicada, pois ela engloba interesses coletivos e como qualquer outra atividade, possui riscos, sendo necessário um grau de tolerância à ação do agente público para sua responsabilização. 
Artigo: Os Limites de Responsabilização do Gestor Público nas Contratações em Virtude da Pandemia de Coronavírus

O erro em momentos de incertezas como vivido atualmente por causa da pandemia de COVID-19 demonstra que a tomada de decisão do agente público poderá acarretar em erro em virtude da situação complexa em que ele se encontra, da necessidade de uma celeridade no processo de decisão uma vez que se trata de salvar vidas e, em decorrência dessa necessidade de salvar vidas, muitas vezes o agente público não conseguirá realizar todas as diligências necessárias, que normalmente leva tempo o que poderá levar ao erro em ocasião de uma decisão que ele achou que seria a mais benéfica para a população brasileira.

O medo recorrente gera um ambiente inseguro ao gestor público que acarretará em prejuízos em sua tomada de decisão o que torna o Estado menos eficaz.

A existência de espaço de tolerância do erro é necessária para que se preserve a eficiência e economicidade das atividades públicas, para que o administrador, em um momento delicado, atue com rapidez e precisão e não com medo em ser responsabilizado por eventuais erros cometidos.

Questões de extrema urgência requerem menos diligências e mais rapidez do que é exigido em situações cotidianas, logo, eventuais erros podem ser justificáveis em virtude da rapidez que a demanda necessitava e também o cargo em que o agente público ocupa.

Por fim, é necessário analisar o caso concreto e ver quando o agente comete erro em virtude das decisões tomadas ou quando ele simplesmente ignora. É preciso ter em mente que o administrador público é um ser capaz de erros como qualquer outro, mas que este também deve tomar suas decisões pautadas na lei.

Em cenários de incertezas deve ser observado o que realmente levou o agente público ao erro. No caso de calamidade pública como vivida atualmente se mostra justificável um espaço maior de tolerância ao erro devido a urgência no processo de decisão, nas informações que ainda não são concretas por parte das autoridades competentes, visto que com frequência é publicada diferentes opiniões a respeito da COVID-19 e o que se deve fazer para conter a disseminação do vírus.

A todo momento a segurança jurídica deve ser preservada, bem como a averiguação do erro ser realizada com a mínima cautela para que se preserve a segurança jurídica e legalidade.

\section{REFERÊNCIAS}

ÁVILA, Humberto. Princípios e regras da segurança jurídica. PDE| Revista de Direito do Estado. Ano 1, nº1: 189.206 jan/mar,2006.

BINENBOJM, Gustavo; DIONISIO, Pedro de Hollanda. O direito ao erro do administrador público e a Covid-19 em contextos de emergência. 2020. Disponível em: https://www.conjur.com.br/2020-abr-04/opiniao-direito-erroadministrador-publico-covid-19. Acesso em: 24 abr. 2021.

BRASIL, Constituição da República Federativa do Brasil de 1988. Brasília. DF. Disponível em: http://www.planalto.gov.br/ccivil_03/constituicao/constituicao.htm Acesso em 17 abr. 2021.

BRASIL, Decreto Legislativo $\mathbf{n}^{\mathbf{0}} 6$ de 20 de março de 2020. Reconhece, para os fins do art. 65 da Lei Complementar $\mathrm{n}^{\circ} 101$, de 4 de maio de 2000, a ocorrência do estado de calamidade pública, nos termos da solicitação do Presidente da República encaminhada por meio da Mensagem nº 93, de 18 de março de 2020. Diário Oficial da União. Brasília, 20 mar 2020. Disponível em https://legis.senado.leg.br/norma/31993957 Acesso em 17 abr. 2021. 
BRASIL, Decreto-Lei no 4,657, de 4 de setembro de 1942. Leis de Introdução às Normas do Direito Brasilerio. Diário Oficial da União. Brasília, 9 set 1942. Disponível em http://www.planalto.gov.br/ccivil_03/decreto-lei/del4657compilado.htm Acesso em 17 de abr. de 2021.

BRASIL, Lei $\mathbf{n}^{\mathbf{0}} \mathbf{1 3 . 9 7 9}$ de 6 de fevereiro de 2020. Dispõe sobre as medidas para enfrentamento da emergência de saúde pública de importância internacional decorrente do coronavírus responsável pelo surto de 2019. Diário Oficial da União , Brasília, 07 fev 2020. Disponível em: http://www.planalto.gov.br/ccivil_03/_ato2019-2022/2020/lei/113979.htm Acesso em 16 abr 2021.

BRASIL, Lei n 8.112, de 11 de dezembro de 1990. Dispõe sobre o regime jurídico dos servidores públicos civis da União, das autarquias e das fundações públicas federais. Diário Oficial da União, Brasília, 19 abr 1991. Disponível em:

http://www.planalto.gov.br/ccivil_03/leis/18112cons.htm Acesso em 16 abril 2021.

BRASIL, Lei no 8.666 de 21 de junho de 1993. Regulamenta o art. 37, inciso XXI, da Constituição Federal, institui normas para licitações e contratos da Administração Pública e dá outras provicências. Diário Oficial da União, Brasília, 22 jun 1993. Disponível em: http://www.planalto.gov.br/ccivil_03/leis/18666cons.htm Acesso em 16 abr 2021.

BRASIL, Lei no 9.784 de 29 de janeiro de 1999. Regulas o processo administrativo punitivo da Administração Pública Federal. Diário Oficial da União, Brasília, 01 fev 1999. Disponível em: http://www.planalto.gov.br/ccivil_03/leis/19784.htm Acesso em 16 abr 2021.

BRASIL, Medida Provisória n⿳0 966, de 13 de maio de 2020. Dispõe sobre a responsabilização dos agentes públicos por ação e omissão em atos relacionados a pandemia de covid-19. Diário Oficial da União. Brasília, 14 mai 2020. Disponível em https://www.in.gov.br/en/web/dou/-/medida-provisoria-n-966-de-13-de-maio-de-2020256734909 Acesso em 17 de abril de 2021.

BRASIL. Lei $\mathbf{n}^{\mathbf{0}}$ 14.035, de 11 de agosto de 2020. Altera a Lei $\mathrm{n}^{\circ} 13.979$, de 6 de fevereiro de 2020, para dispor sobre procedimentos para a aquisição ou contratação de bens, serviços e insumos destinados ao enfrentamento da emergência de saúde pública de importância internacional decorrente do coronavírus responsável pelo surte de 2019. Diário Oficial da União, Brasília, 12 ago 2021. Disponível em: https://www.in.gov.br/en/web/dou/-/lei-n14.035-de-11-de-agosto-de-2020- 271717691 Acesso em 17 abril 2021.

BRASIL. Supremo Tribunal Federal. Ação Direta de Inconstitucionalidade 6341. Referendo Em Medida Cautelar Em Ação Direta Da Inconstitucionalidade. Direito Constitucional. Direito À Saúde. Emergência Sanitária Internacional. Lei 13.979 De 2020. Competência Dos Entes Federados Para Legislar E Adotar Medidas Sanitárias De Combate À Epidemia Internacional. Hierarquia Do Sistema Único De Saúde. Competência Comum. Requerente: Partido Democrático Trabalhista. Intimado: Presidente da República. Relator: Min Marco Aurélio, 15 de abril de 2020. Disponível em:http://portal.stf.jus.br/processos/downloadPeca.asp?id=15344964720\&ext=.pdf Acesso em 19 de abril de 2021.

BRASIL. Ação Direta de Inconstitucionalidade 6421. Direito Administrativo. Ações Diretas De Inconstitucionalidade. Responsabilidade Civil E Administrativa De Agentes 
Artigo: Os Limites de Responsabilização do Gestor Público nas Contratações em Virtude da Pandemia de Coronavírus

Públicos. Atos Relacionados À Pandemia De Covid-19. Medida Provisória No 966/2020.

Deferimento Parcial Da Cautelar. Requerente: Rede Sustentabilidade. Intimado: Presidente da República. Relator: Min Marco Aurélio, 21 de maio de 2020. Disponível em:

http://portal.stf.jus.br/processos/downloadPeca.asp?id=15344951 023\&ext=.pdf Acesso em 19 de abril de 2021.

BRASIL. Ação Direta de Inconstitucionalidade 6422. Direito Administrativo. Ações Diretas De Inconstitucionalidade. Responsabilidade Civil E Administrativa De Agentes Públicos. Atos Relacionados À Pandemia De Covid-19. Medida Provisória Nº 966/2020. Deferimento Parcial Da Cautelar. Requerente: Partido Popular Socialista. Intimado: Presidente da República. Relator: Min Roberto Barroso, 21 de maio de 2020. Disponível em: http://portal.stf.jus.br/processos/downloadPeca.asp?i d=15344951151\&ext=.pdf Acesso em 19 de abril de 2021.

BRASIL. Ação Direta de Inconstitucionalidade 6424. Direito Administrativo. Ações Diretas De Inconstitucionalidade. Responsabilidade Civil E Administrativa De Agentes Públicos. Atos Relacionados À Pandemia De Covid-19. Medida Provisória No 966/2020. Deferimento Parcial Da Cautelar. Requerente: Partido Socialismo e Liberdade (P-SOL). Intimado: Presidente da República. Relator: Min Roberto Barroso, 21 de maio de 2020. Disponível em: http://portal.stf.jus.br/process os/downloadPeca.asp?id=15344951302\&ext=.pdf Acesso em 19 de abril de 2021.

BRASIL. Ação Direta de Inconstitucionalidade 6425. Direito Administrativo. Ações Diretas De Inconstitucionalidade. Responsabilidade Civil E Administrativa De Agentes Públicos. Atos Relacionados À Pandemia De Covid-19. Medida Provisória No 966/2020. Deferimento Parcial Da Cautelar. Requerente: Partido Comunista do Brasil Intimado: Presidente da República. Relator: Min Roberto Barroso, 21 de maio de 2020. Disponível em: http://portal.stf.jus.br/processos/downloadPeca. asp?id=15344964396\&ext=.pdf . Acesso em 19 de abril de 2021.

BRASIL. Ação Direta de Inconstitucionalidade 6427. Direito Administrativo. Ações Diretas De Inconstitucionalidade. Responsabilidade Civil E Administrativa De Agentes Públicos. Atos Relacionados À Pandemia De Covid-19. Medida Provisória Nº 966/2020. Deferimento Parcial Da Cautelar. Requerente: Associação Brasileira de Imprensa. Intimado: Presidente da República. Relator: Min Roberto Barroso, 21 de maio de 2020. Disponível em: http://portal.stf.jus.br/processos/downloadPeca .asp?id=15344964488\&ext=.pdf Acesso em 19 de abril de 2021.

BRASIL. Tribunal de Contas da União. Acórdão 2391/2018, Rel. Benjamin Zymler, Plenário. DJ 17/10/2018. Disponível em https://pesquisa.apps.tcu.gov.br/\#/docu mento/acordao-completo/2391\%252F2018/\%2520/DTRELEVANCIA\%2520d esc\%252C\%2520NUMACORDAOINT\%2520desc/0/\%2520 Acesso em 19 de abril de 2021.

CARVALHO FILHO, Jose dos Santos. Manual de Direito Administrativo. 34. ed. São Paulo: Atlas Ltda., 2020.

CASTROVIEJO, Gabriela Gomes Acioli. Coronavírus (COVID-19) e Dispensa de Licitação: análise sob à ótica da Lei 13.979/2020. 2020. Disponível em: https://ambitojuridico.com.br/cadernos/direito-administrativo/coronavirus-covid-19- 
edispensa-de-licitacao-analise-sob-a-otica-da-lei-13-979-2020/\#_ftn9. Acesso em: 24 abr. 2021.

CYRINO, André; BINENBOJM, Gustavo. O Art. 28 da LINDB: a cláusula geral do erro administrativo. Revista de Direito Administrativo: Direito Público na Lei de Introdução às Normas do Direito Brasileiro - LINDB (Lei no 13.655/2018), Rio de Janeiro, p. 203-221, out. 2018. Disponível em:

https://edisciplinas.usp.br/pluginfile.php/4605286/mod_resource/content/1/binenbojm $\% 2 \mathrm{C} \% 20$ gustavo\%3B\%20cyrino\%2C\%20Andr\%C3\%A9\%20-\%20a\%20cl\%C3\%A1 usula\%20geral\%20do\%20erro\%20administrativo.pdf. Acesso em: 14 abr. 2020.

DIONISIO, Pedro de Hollanda. O Direito ao Erro do Administrador Público no Brasil: contexto, fundamentos e parâmetros. Rio de Janeiro: Gz, 2019

JORGE, Flávio Cheim; BELIQUI, Mariana Fernandes. As contratações públicas em tempos de pandemia em sintonia com a futura "Nova Lei de Licitações". 2020. Disponível em: https://www.migalhas.com.br/depeso/328111/as-contratacoespublicas-em-tempos-depandemia-em-sintonia-com-a-futura--nova-lei-de-licitacoes. Acesso em: 24 abr. 2021.

MENDES, Gilmar Ferreira. Série IDP - Curso de Direito Constitucional. 13. Ed. São Paulo Editora Saraiva, 2018.

ORGANIZAÇÃO MUNDIAL DE SAÚDE DECLARA PANDEMIA DO NOVO CORONAVÍRUS: Mudança de classificação obriga países a tomarem atitudes preventivas. Ascom Se/Una-Sus, 11 mar. 2020. Disponível em:

https://www.unasus.gov.br/noticia/organizacao-mundial-de-saude-declara-pandemiadecoronavirus. Acesso em: 16 abr. 2021.

PIETRO, Maria Syilvia Zanella Di. Direito Administrativo. 27. Ed. Rio de Janeiro. Forense LTDA., 2014.

PIETRO, Maria Syilvia Zanella Di. Direito Administrativo. 33. ed. Rio de Janeiro: Forense Ltda., 2020.

SANTOS, Rodrigo Valgas dos. Direito Administrativo do Medo: risco e fuga da responsabilização dos agentes públicos. São Paulo: Revista dos Tribunais, 2020. 